ISSN: 2711-1792 (En línea) • Espacio Matemático Vol. 1 No. 2 (2020), pp. 74-91

\title{
The Math Kangaroo Competition
}

\author{
M. Akveld, L. Cáceres, J. H. Nieto, R. Sánchez
}

\begin{abstract}
In this paper we briefly explain what Math Kangaroo is. This is followed by a representative sample of Kangaroo questions, varying over all ages and all areas of mathematics that are covered by this competition. The paper concludes with the analysis of some statistical data and suggestions about how Math Kangaroo and this type of questions may be used in Math Clubs.
\end{abstract}

Key words and phrases: AKSF, mathematical competitions, problems, multiple choice.

\section{La competencia Canguro Matemático}

\section{Resumen}

En este artículo explicamos brevemente lo que es el Canguro Matemático. A esto le sigue una muestra representativa de preguntas del Canguro, que varían sobre todas las edades y todas las áreas matemáticas que cubre esta competencia. El artículo concluye con el análisis de algunos datos estadísticos y con sugerencias sobre cómo el Canguro Matemático y este tipo de preguntas pueden ser usados en Clubes de Matemática.

Palabras y frases clave: AKSF, competencias matemáticas, problemas, selección múltiple.

\section{Description of Math Kangaroo competition}

Math Kangaroo is a multiple choice mathematics competition for grades 112 held every year on the third Thursday of March. More than 80 countries around the world and over 6 million children participate.

\subsection{History of Math Kangaroo}

You may wonder why a Math competition carries the name Kangaroo and what its relation is with the animals hopping around in Australia. The reason 
ISSN: 2711-1792 (En línea) • Espacio Matemático Vol. 1 No. 2 (2020), pp. 74-91

is simple: the contest was first held in France in 1991 and it was named kangourou because the contest format drew from the previously held Australian Mathematics Competition (see [1] and [2]). As Math Kangaroo became very popular among students, the contest has first spread from France to European countries, and has further expanded around the world. Now, Math Kangaroo is coordinated globally by Association Kangourou Sans Frontières (AKSF). In 2020 more than 6 million children participated from almost 90 countries all around the globe (for the exact statistics see [1]), becoming the largest international mathematics competition in the world.

\subsection{Goal and structure of AKSF}

What is the secret of this success? The most important and clearly declared goal of the AKSF is to popularise mathematics and the way this is done is by organising the annual competition Math Kangaroo on the same day, namely the third Thursday in March, everywhere on the world. The competition is organised in 6 age levels covering grades 1-12. Each level consists of 24 to 30 multiple choice questions divided up in $3-, 4-$ and 5-point problems depending on the difficulty. The idea is that every student will be able to answer some problems. The competition is not designed to search for mathematical talent, but to share the beauty and joy of mathematics with all. How is this achieved? The questions are selected at the annual meeting of AKSF at which working groups consisting of mathematicians and math educators from all over the world deliberate on the data base of questions that has been submitted and rated before the meeting. The questions are not standard textbook problems and come from a large variety of topics. Besides inspiring ideas, perseverance and creativity, they require imagination, basic computational skills, logical thinking and other problem solving strategies. Often there are small stories, surprising questions and results, which encourage discussions with friends and family. The organisation of the competition in the individual countries is up to the members of AKSF.

\section{Problems}

In this section we present a selection of Math Kangaroo problems from [3]. We have ordered them in five sections: Geometry, Number Theory, Combinatorics, Algebra and Other. Each question is labelled by a category, a year 
and a number. The category denotes the age group (Pre Ecolier, Ecolier, Benjamin, Cadet, Junior and Student), the year denotes when it appeared on the Kangaroo paper and the number denotes its position on the paper. The higher the number the harder the problem.

\subsection{Geometry}

Kangaroo geometry problems stress visualization, symmetry and simple calculations involving lengths, angles and areas.

Pre Ecolier, 2018-12. Lisa has 4 pieces, but she only needs 3 for her puzzle frame.

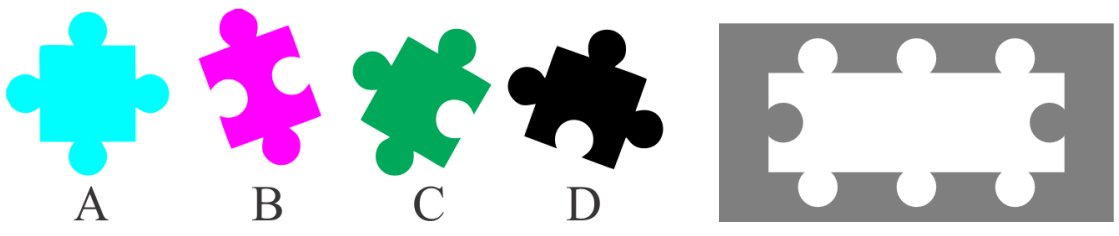

Which one will be left over?
(A) $\mathrm{A}$;
(B) $\mathrm{B}$;
(C) $\mathrm{C}$;
(D) $\mathrm{D}$;
(E) $\mathrm{C}$ or D.

Ecolier, 2019-20. A hallway has the dimensions shown in the picture.

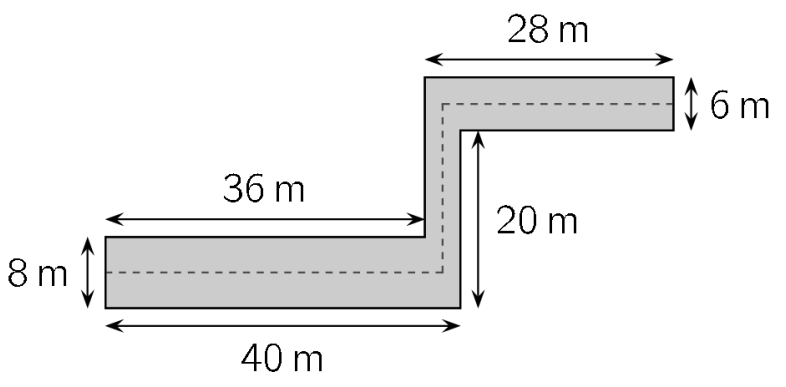

A cat walks on the dashed line along the middle of the hallway. How many metres does the cat walk?
(A) 63 ;
(B) 68 ;
(C) 69 ;
(D) 71 ;
(E) 83 .

Benjamin, 2018-6. A star is made of four equilateral triangles and a square. The perimeter of the square is $36 \mathrm{~cm}$. What is the perimeter of the star? 


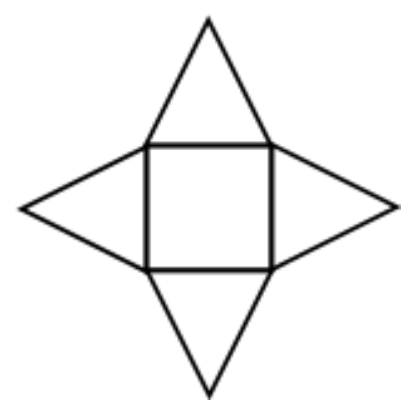
(A) $144 \mathrm{~cm}$;
(B) $120 \mathrm{~cm}$;
(C) $104 \mathrm{~cm}$;
(D) $90 \mathrm{~cm}$;
(E) $72 \mathrm{~cm}$.

Cadet, 2019-29. The diagram shows the square $A B C D$ with $P, Q$ and $R$ the midpoints of the sides $D A, B C$ and $C D$ respectively.

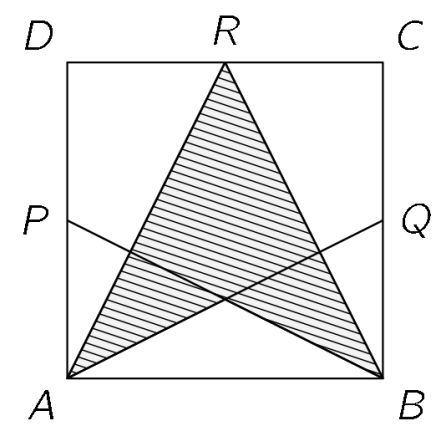

What fraction of the square $A B C D$ is shaded?
(A) $\frac{3}{4}$;
(B) $\frac{5}{8}$;
(C) $\frac{1}{2}$;
(D) $\frac{7}{16}$;
(E) $\frac{3}{8}$.

Junior, 2018-13. Eight congruent semicircles are drawn inside a square of length 4 .

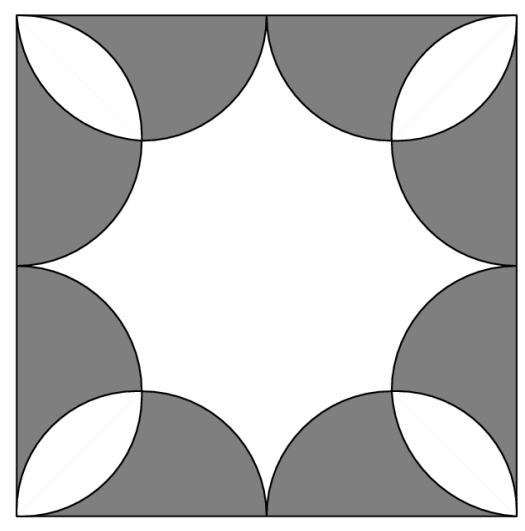


What is the area of the non-shaded part of the square?
(A) $2 \pi$;
(B) 8 ;
(C) $6+\pi$;
(D) $3 \pi-2$;
(E) $3 \pi$.

Student, 2019-18. Two adjacent squares with side lengths $a$ and $b(a<b)$ are shown. What is the area of the shaded triangle?

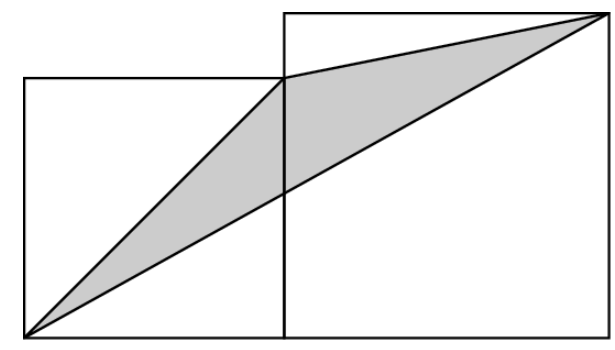
(A) $\sqrt{a b}$;
(B) $\frac{1}{2} a^{2}$;
(C) $\frac{1}{2} b^{2}$;
(D) $\frac{1}{4}\left(a^{2}+b^{2}\right)$;
(E) $\frac{1}{2}\left(a^{2}+b^{2}\right)$.

\subsection{Number Theory}

Kangaroo Number Theory problems deal with arithmetic, decimal representations, divisibility properties and prime numbers.

Pre Ecolier, 2018-20. A pirate has two chests. There are 10 coins in the left chest and the other is empty. Starting tomorrow, the pirate will put 1 coin in the left chest and 2 coins in the other one every day. In how many days will the two chests have the same number of coins?
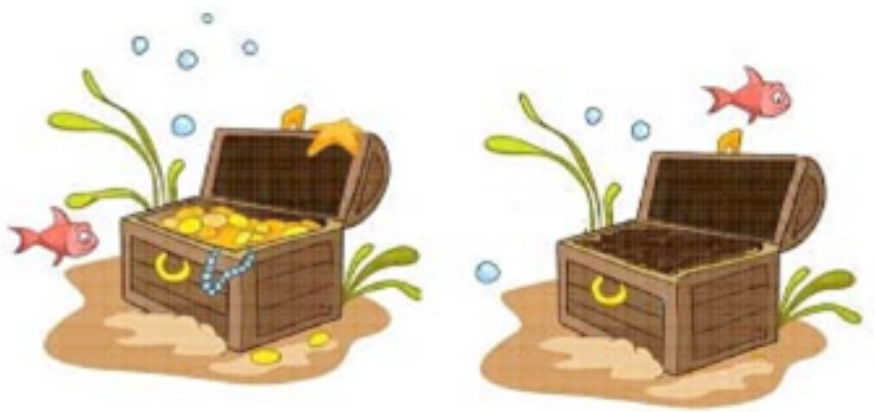
(A) 5 ;
(B) 8 ;
(C) 10 ;
(D) 12 ;
(E) never.

Ecolier, 2019-8. What number should replace the question mark when all the calculations are completed correctly? 


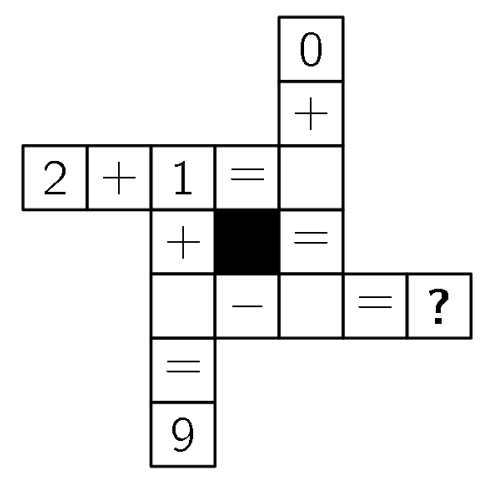
(A) 4
(B) $5 ;$ (C) 6 ;
(D) 7 ;
(E) 8 .

Benjamin, 2018-5. Alice subtracted two 2-digit numbers. Then she painted two cells.

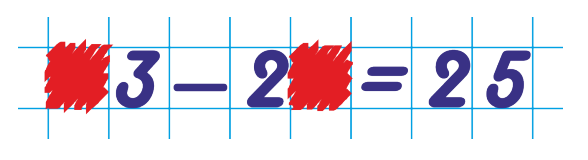

What is the sum of the two digits in the painted cells?
(A) 8
(B) 9 ;
(C) 12 ;
(D) 13 ;
(E) 15 .

Cadet, 2019-11. A four-digit integer is written on each of three pieces of paper. The pieces of paper are arranged so that three of the digits are covered, as shown.

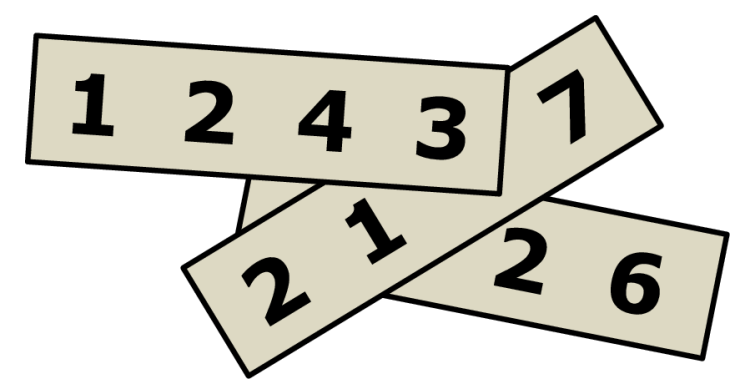

The sum of the three four-digit integers is 10126. Which are the covered digits?

(A) 5,6 and 7; (B) 4, 5 and 7; (C) 4,6 and 7; (D) 4, 5 and 6; (E) 3,5 and 6 . 
Junior, 2019-28. What is the least number of elements we have to delete from the set $\{10,20,30,40,50,60,70,80,90\}$ so that the product of the elements remaining in the set is a perfect square?
(A) 1 ;
(B) 2 ;
(C) 3;
(D) 4 ;
(E) 5 .

Student, 2018-19. Three of the five cards shown are given to Nadia and the rest to Riny. Nadia multiplies the 3 values of her cards and Riny multiplies the 2 values of his cards. It turns out that the sum of the two resulting products is prime. What is the sum of the values of Nadia's cards?

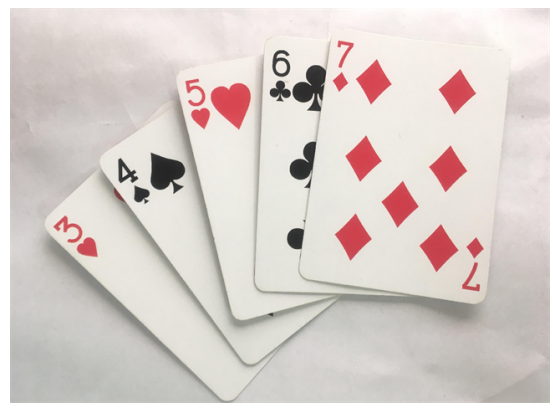
(A) 12 ;
(B) $13 ;$ (C) 15 ;
(D) 17 ;
(E) 18 .

\subsection{Combinatorics}

Kangaroo Combinatorics problems deal mostly with enumeration of finite sets, binary relations (which may be represented by graphs) and dynamic situations involving moves, such as games.

Cadet, 2019-14. Alan, Bella, Claire, Dora, and Erik met at a party and shook hands exactly once with everyone they already knew. Alan shook hands once, Bella shook hands twice, Claire shook hands three times and Dora shook hands four times. How many times did Erik shake hands?
(A) 1 ;
(B) $2 ;$ (C) 3 ;
(D) 4 ;
(E) 0 .

Junior, 2019-25. A graph consists of 16 vertices and some edges that connect them, as in the picture. An ant is now at the vertex labelled $A$. At each move, it can walk from one vertex to any neighbouring vertex crawling along a connecting edge. At which of the vertices labelled $P, Q, R, S, T$ can the ant be after 2019 moves? 


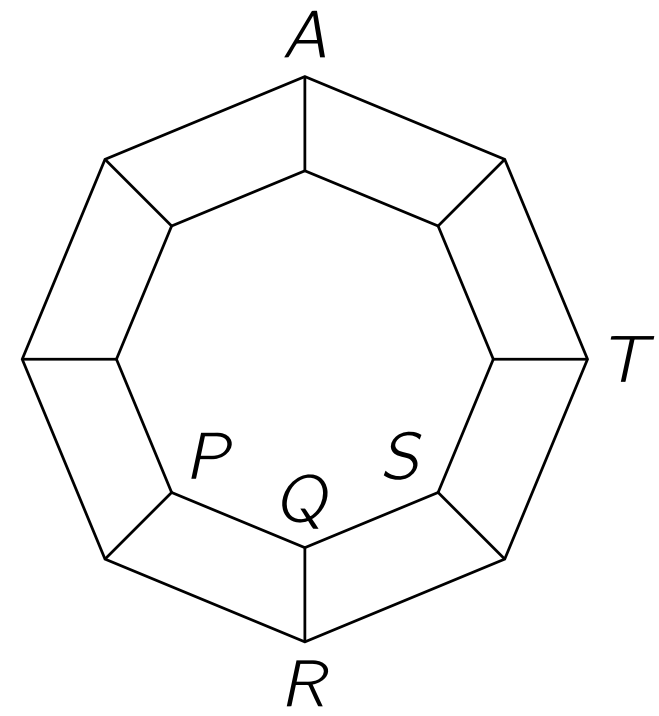

(A) only $P, R$ or $S$, not $Q$ and $T$; (B) only $P, R, S$ or $T$, not $Q$;

(C) only $Q$; (D) only $T$; (E) all of these are possible.

Student, 2018-8. There are 65 balls in a box. 8 are white and the rest of the balls are black. In one move, at most 5 balls can be taken out of the box. It is not allowed to put any balls back in the box. What is the smallest number of moves needed to ensure that at least one white ball is taken out?

(A) $11 ;$ (B) $12 ;$ (C) $13 ;$ (D) $14 ;$ (E) 15 .

\subsection{Algebra}

Kangaroo Algebra problems can generally be solved with simple linear equations or systems. In the higher levels you may come across quadratics, more complex systems, coordinates and equations of lines and circles.

Cadet, 2019-27. When Ria and Flora compared their savings, they found that the ratio of their savings was $5: 3$. Then Ria bought a tablet for 160 Euro and the ratio of their savings changed to $3: 5$. How many Euro did Ria have before buying the tablet?
(A) 192 ;
(B) 200 ;
(C) 250 ;
(D) 400 ;
(E) 420 .

Junior, 2019-15. The triathlon consists of swimming, running, and biking. The biking is three-quarters of the total distance; the running is one-fifth; 
and the swimming is $2 \mathrm{~km}$. What is the total distance of this triathlon, in $\mathrm{km}$ ?
(A) 10 ;
(B) 20 ;
(C) 38 ;
(D) 40 ;
(E) 60 .

Student, 2019-25. Four distinct straight lines pass through the origin of the coordinate system. They intersect the parabola $y=x^{2}-2$ at eight points. What can be the product of the $x$-coordinates of these eight points?

(A) only 16; (B) only -16; (C) only 8; (D) only -8 ;

(E) There are several possible products..

\subsection{Other}

Here we group logic problems, problems involving patterns and some problems which do not belong in another single area.

\section{Pre Ecolier, 2019-11.}

Five square cards are stacked on a table, as shown.

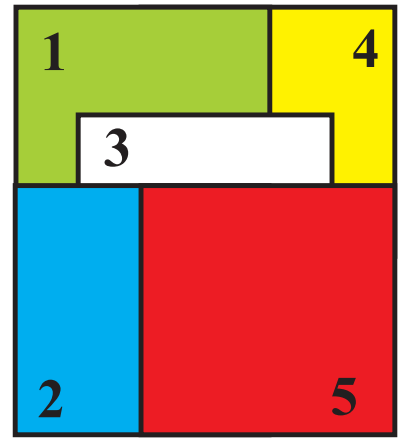

The cards are removed one by one from the top of the stack. In what order are the cards removed?

(A) 1-2-3-4-5; (B) 5-2-3-4-1; (C) 4-5-2-3-1; (D) 5-3-2-1-4; (E) 5-2-3-1-4.

Benjamin, 2018-28. 14 people are seated at a round table. Each person is either a liar or tells the truth. 


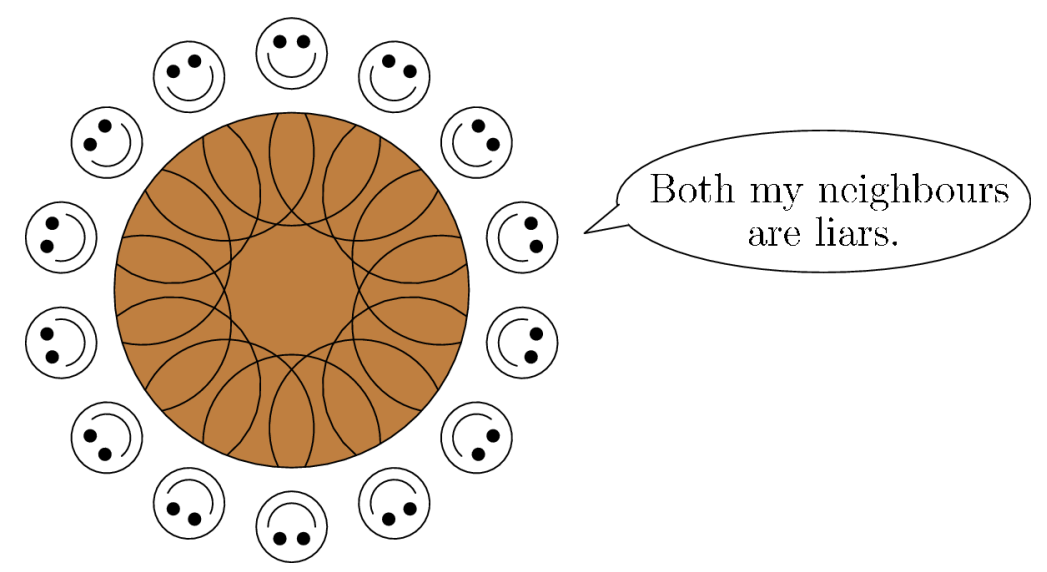

Everybody says: "Both my neighbours are liars". What is the maximum number of liars at the table?
(A) 7 ; (B) 8 ; (C) 9 ;
(D) 10 ;
(E) 14 .

Junior, 2018-29. Ed made a large cube by gluing together a number of small identical cubes and then he painted some of the faces of the large cube. His sister Nicole dropped the cube and it broke into the original small cubes. 45 of these small cubes didn't have any painted faces. How many faces of the large cube did Ed paint?
(A) 2 ;
(B) 3 ;
(C) 4 ;
(D) 5 ;
(E) 6 .

Student, 2018-6. The following two statements are true: Some aliens are green, the others are purple. Green aliens live only on Mars. Therefore, it logically follows that

(A) all aliens live on Mars.; (B) only green aliens live on Mars.; (C) some purple aliens live on Venus.; (D) all purple aliens live on Venus.; (E) no green aliens live on Venus..

\section{Some statistics}

We did an analysis of the mathematical area of each of the problems in the six levels for the 2020 papers, [4]. The areas we used for classification are Geometry, Algebra, Combinatorics, Number Theory and Other. In the case of Other we have problems in logic and patterns. In the first levels of the competition we include elementary Arithmetic along with Number Theory. 


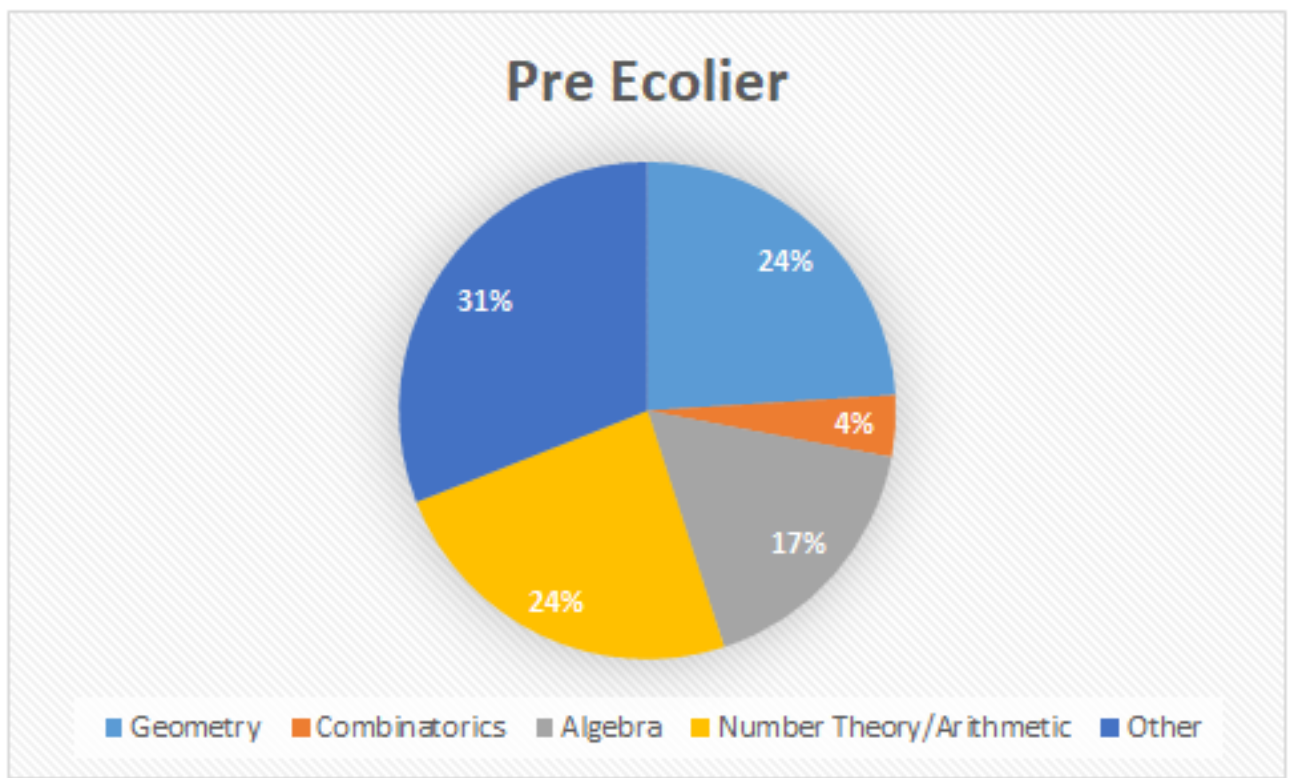

Figure 1: Areas in Pre-Ecolier problems

In the Pre Ecolier level (Fig. 1) the Other area predominates with 31\%, followed by Geometry and Number Theory (Arithmetic), each one with $24 \%$ of the questions. On the other hand, $17 \%$ of the questions are in Algebra and the remaining questions are in Combinatorics, the latter category having the least amount of questions. Nevertheless if we add the percentages of Geometry, Other and Combinatorics, we get 59\%.

The main area in Ecolier (Fig. 2) is Geometry, with $29 \%$ of the questions, followed by Other with $24 \%$ and Combinatorics with $22 \%$. Number Theory has $14 \%$ and Algebra 11\%. Again adding the percentages of Geometry, Others and Combinatorics we get $75 \%$.

In Benjamin (Fig. 3) Other has $27 \%$ of the questions, Geometry $25 \%$ and Combinatorics 25\%. Algebra has $16 \%$ and Number Theory $7 \%$. Here the sum of the three, Geometry, Others and Combinatorics reaches the $77 \%$.

In Cadet (Fig. 4) almost one third of the questions are in Geometry (31\%), followed by Number Theory and Algebra with 22\% each. Other has $15 \%$ and Combinatorics only 10\%. Combinatorics, Geometry and Others, add up to $56 \%$

In the Junior level (Fig. 5) 31\% of the questions are in the area of Geom- 


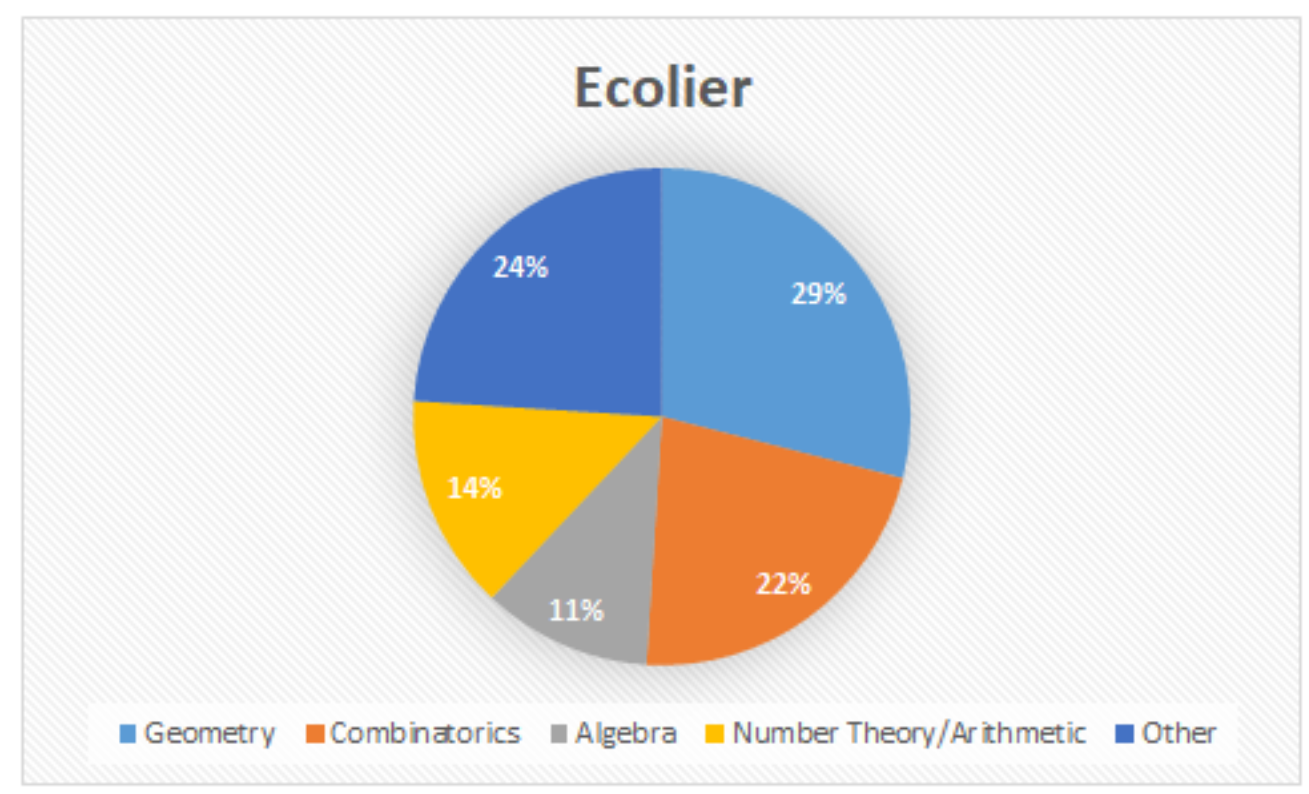

Figure 2: Areas in Ecolier problems

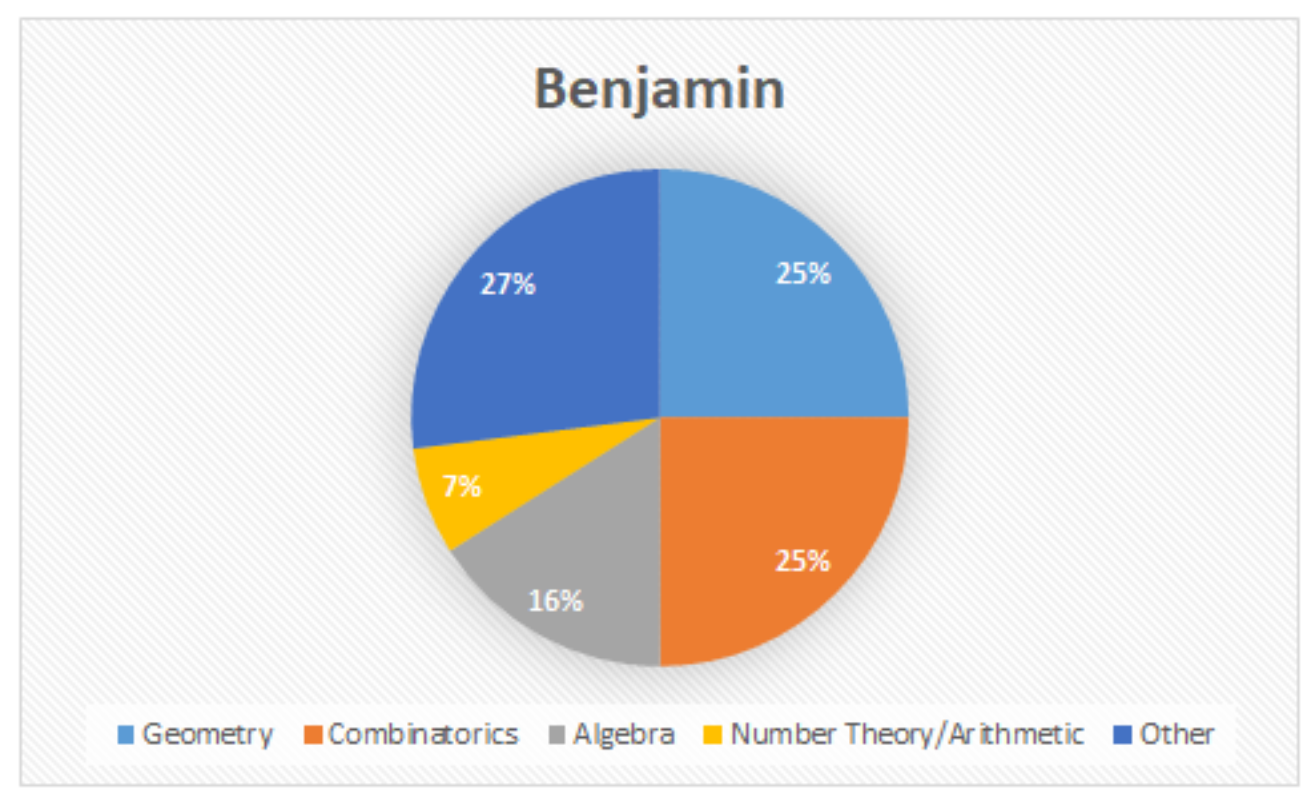

Figure 3: Areas in Benjamin problems 


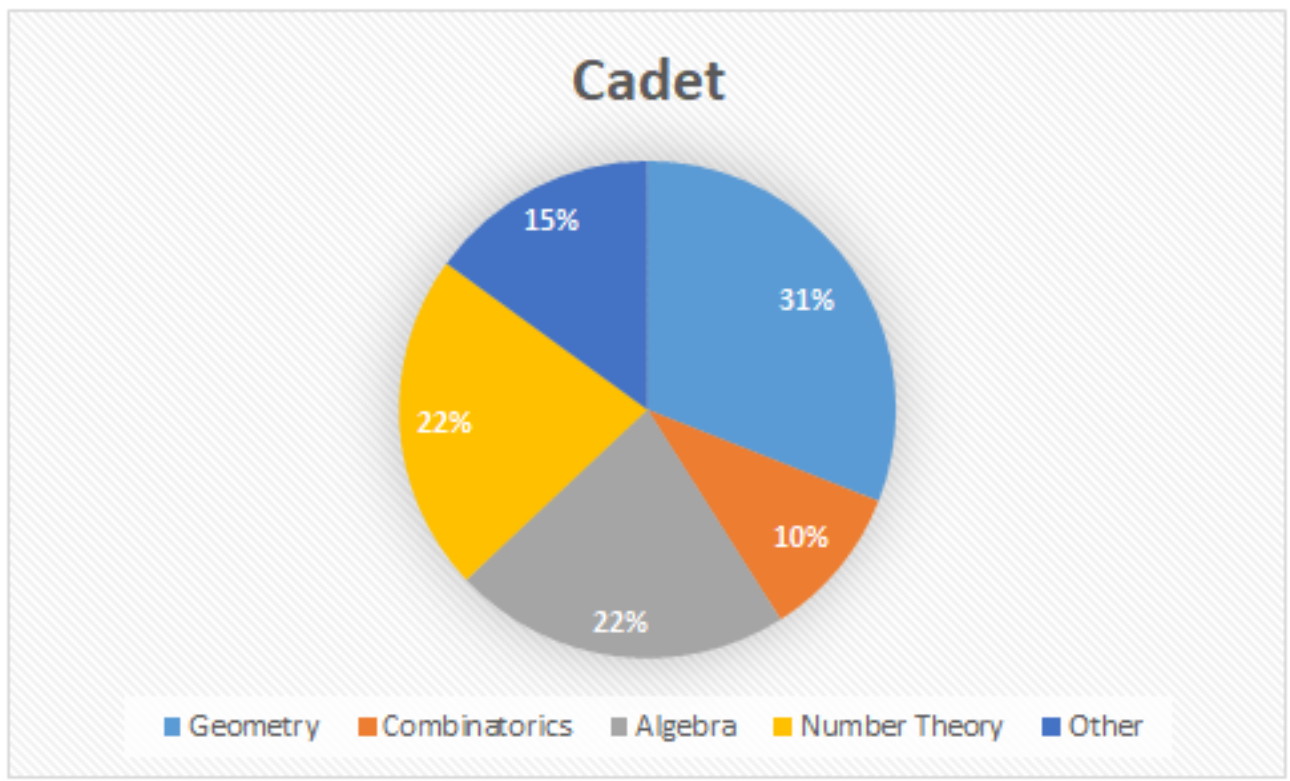

Figure 4: Areas in Cadet problems

etry and $28 \%$ in Number Theory, followed by Other with $20 \%$. On the other hand, $18 \%$ of the questions are in Algebra and only 3\% in Combinatorics. Although Combinatorics just have the 3\%, again together with Geometry and Others, they have more than $50 \%$, exactly $54 \%$.

At the Student level (Fig. 6) the areas of Number Theory and Geometry clearly predominate, each one with around one third of the questions. The other third is shared by Combinatorics and Algebra, each one with a $13 \%$, and Other with $7 \%$. In this level, as in all the previous, Combinatorics, Geometry and Others have more than $50 \%$ of the total, reaching the $52 \%$.

Clearly, the main area in all levels (Fig. 7) is Geometry. In the first levels, such as Pre Ecolier, Ecolier and Benjamin, problems are more mixed between areas, for example, the same problem can simultaneously cover geometry, patterns and logic. Of course, this is true in all levels, but it is more notorious at the younger levels. In the superior levels, Junior and Student, Geometry and Number Theory cover more than $60 \%$ of the questions, but in general, as we pointed out, questions in Combinatorics, Geometry and Others, together, outweigh the other areas. This is also interesting if you compare to standard curricula. At the age of the Junior or Student papers, 


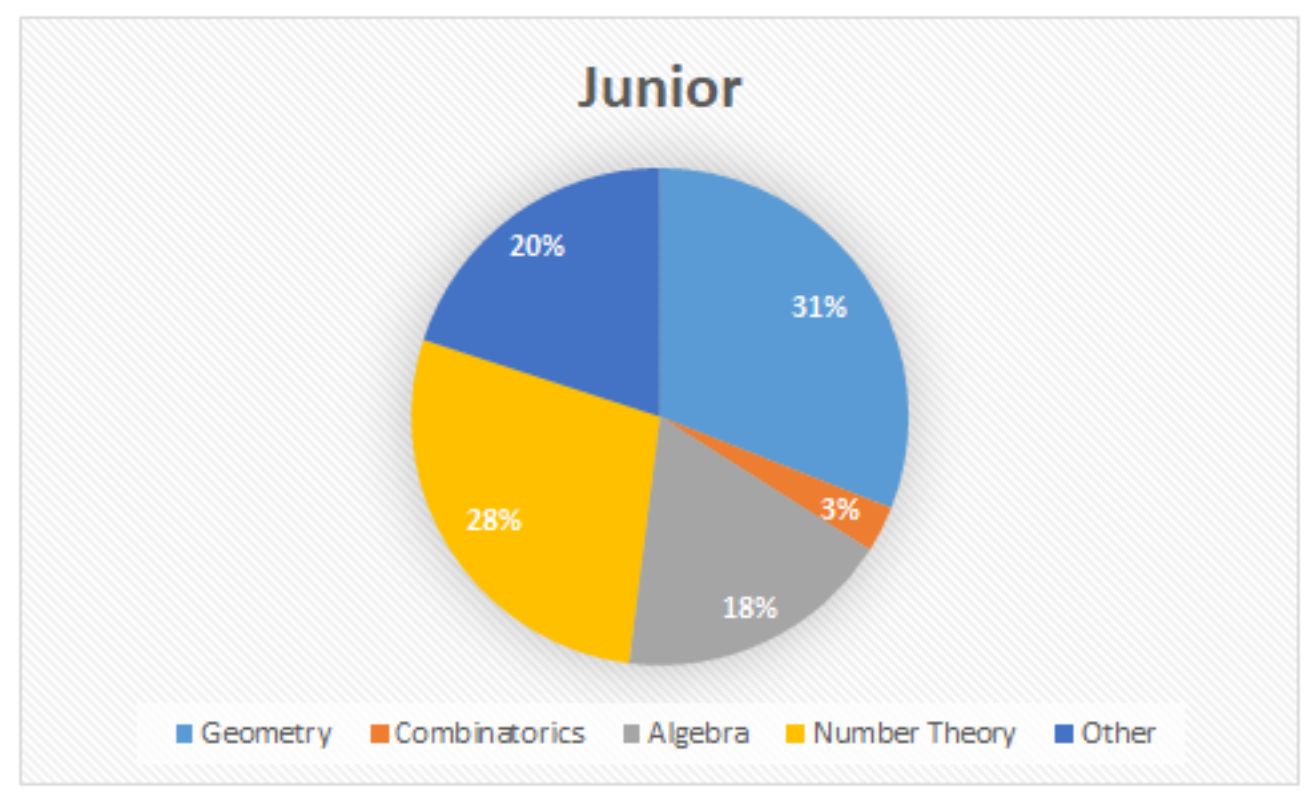

Figure 5: Areas in Junior problems

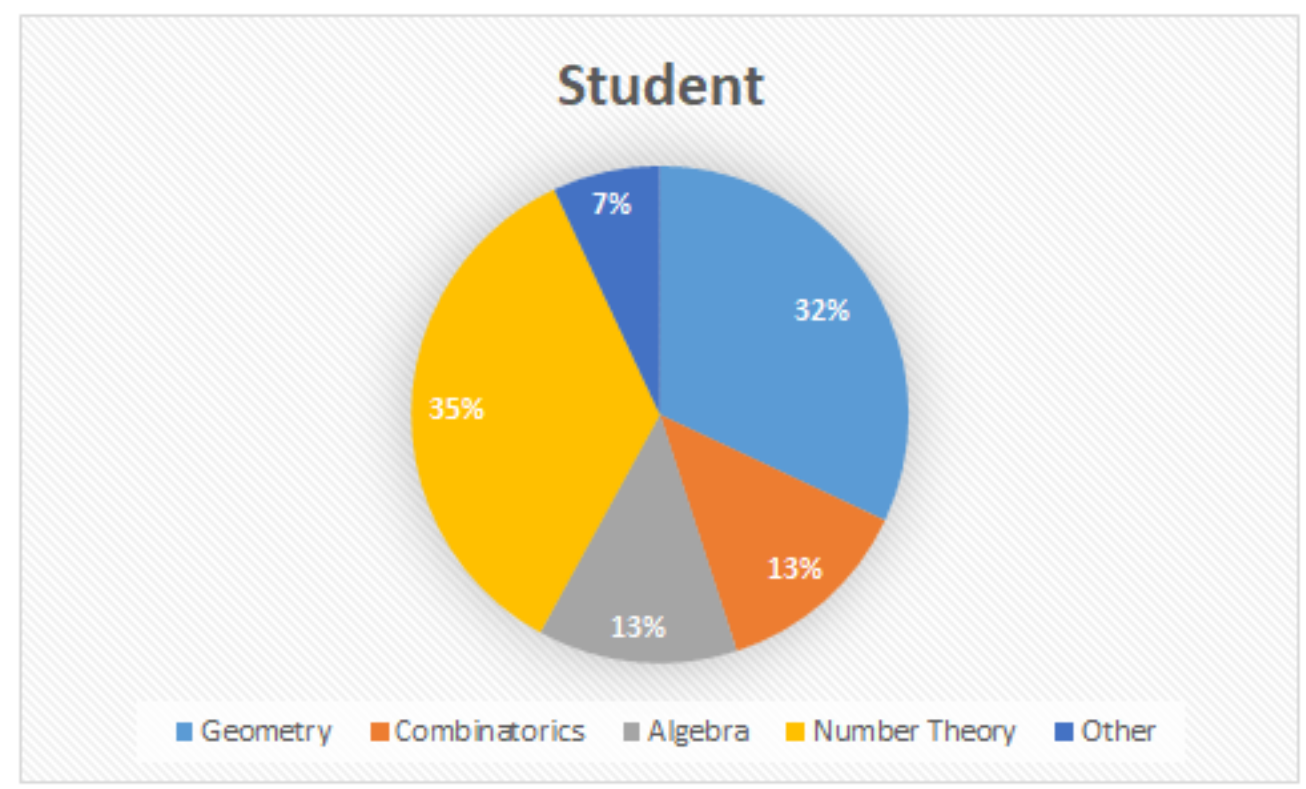

Figure 6: Areas in Student problems 


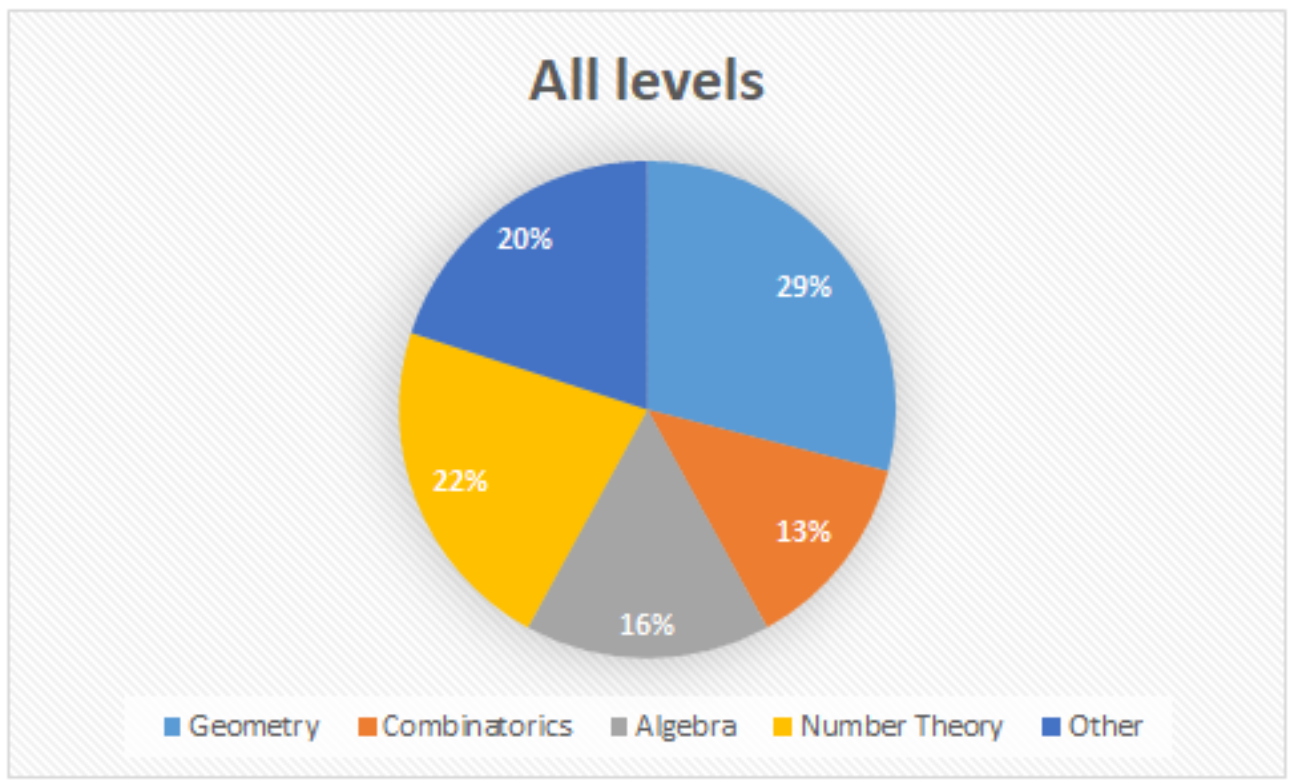

Figure 7: Areas in all levels problems

students are mainly occupied in school with solving calculus and pre-calculus problems. As claimed above, Kangaroo excels with non-standard textbook problems which makes it once more very interesting for Math Clubs, where - as in Kangaroo - mathematical thinking is more in focus than solving problems by standard methods and algorithms.

\section{Use of Math Kangaroo in Math Clubs}

A Math Club is a group of people getting together to learn and play with math. This is an extracurricular math activity that can come in all shapes and sizes. There is no one model that works for every school. The common denominator is that all of them focus on two things: having fun and learning math. An example of these are math circles, where students and experienced leaders get together after school or on weekends, to work on problems, math games or topics in mathematics.

As Math Kangaroo is a fun competition with popularisation of mathematics as its main goal, we think it actually fits very well in the concept of 
ISSN: 2711-1792 (En línea) • Espacio Matemático Vol. 1 No. 2 (2020), pp. 74-91

a Math Club. The light version would consist that a Math Club takes part in the competition, for more information see [5]. However, we think there could be much more to benefit from. Depending on how used students are to multiple choice questions it certainly makes sense to prepare them for this and to go through some old papers. Of course one can also use the enormous amount of questions collected in the previous 25 years in Math Clubs activities. Often questions are related, appear over different age categories in different forms and difficulties and can be considered as enough material for one particular Math Club session. And finally, once the competition is done, of course students may want to know what the answers are to the questions. One can either wait for the official results or work them out together with students. This is certainly a fun activity and may bring plenty of new ideas to Math Clubs.

\section{Conclusions}

Summing up we have come to the following conclusions:

- Math Kangaroo helps to popularize math between students, their families and their teachers.

- Math Kangaroo problems are originals and they collect the experience of teachers from different cultures.

- Math Kangaroo problems collection gives teachers around the world an extraordinary tool to improve their teaching and these problems allow the teachers to present Math in a recreational way.

- Math Kangaroo problems motivate mathematical logical thinking from an early age.

- Math Kangaroo contest proposes problems whose solution requires more ingenuity than knowledge. This explains why the percentage of problems in Combinatorics, Geometry and Others, together, is in general, higher than problems in Algebra and Number Theory.

- Math Kangaroo problems build a huge potential for Math Clubs, as they are a rich source of inspiring and non standard questions. 


\section{Answers to Sample Problems}

Geometry. Pre-Ecolier: A; Ecolier: E; Benjamin: E; Cadet: E; Junior: B; Student: B.

Number Theory. Pre-Ecolier: C; Ecolier: B; Benjamin: D; Cadet: A; Junior: B; Student: B.

Combinatorics. Cadet: B; Junior: C; Student: B.

Algebra. Cadet: C; Junior: D; Student: A.

Other. Pre-Ecolier: E; Benjamin: C; Junior: C; Student: E.

\section{Acknowledgements}

We would like to thank the AKSF for allowing us to use their problems and their data.

\section{References}

1. Website Association Kangourou Sans Frontières, www.aksf.org

2. Francisco Bellot Rosado, Un Concurso Matemático distinto: El Canguro Matemático, Boletín de la Asociación Matemática Venezolana, Vol. VIII, No. 1 (2001), www.emis.de/journals/BAMV/conten/vol08/ fbellot.pdf

3. Selected questions from the Kangaroo competition of the years 20182019 .

4. Selected questions from the Kangaroo competition 2020.

5. Website US Math Kangaroo, www.mathkangaroo.org 
Meike Akveld (meike.akveld@math.ethz.ch)

ETH Zürich, Switzerland

Luis Cáceres Duque (luis.caceres1@upr.edu)

University of Puerto Rico at Mayagüez

José Heber Nieto Said (jhnieto@gmail.com)

Universidad del Zulia, Maracaibo, Venezuela

Rafael Sánchez Lamoneda(lamonedar@gmail.com)

Universidad Antonio Nariño, Bogotá, Colombia 